\title{
Evaluation of Knowledge and Competence of Kazakhstani Athletes about Nutrition
}

\author{
Yeldana Yerzhanova ${ }^{1}$, Zhanna Sabyrbek ${ }^{1}$, Ermek Dilmakhanbetov ${ }^{1}$, Galiya Madiyeva ${ }^{1}$ and Kazys Milasius ${ }^{2}$ \\ ${ }^{1}$ Al-Farabi Kazakh National University, Faculty Medicine and Health, Almaty, Kazakhstan, ${ }^{2}$ Vytautas Magnus University, Faculty Sport and Health, \\ Kaunas, Lithuania
}

\begin{abstract}
Knowledge and competences are important for every person, especially they are important for physically active people. Although the knowledge and competence of athletes about nutrition is investigated, this subject is still a relatively new area in the science of nutrition of Kazakhstan athletes. Knowledge and competence is characterized as the ability of an individual to obtain, process and understand basic information on nutrition. The purpose of the work is to determine the level of knowledge, sources and the method of their acquisition by the investigated athletes. 199 students from Al-Farabi Kazakh National University and Abay Kazakh National Pedagogical University were enrolled in 1-4 courses in physical education and sports and 60 athletes of high sportsmanship - 15 volleyball players of Burevestnik teams, 15 judo wrestlers of the Kazakhstan national team, 15 wrestlers of the club team and 15 triathletes of the Kazakhstan national team were engaged in the study of the level of knowledge, method of acquisition of information on nutrition. The questionnaire prepared by Steptoe et al., (1995) was applied during the survey of students, directly interviewing each respondent. Kazakhstani athletes get basic information on nutrition from trainers and family members, and too few are accounted for by doctors and nutritionists. Public information systems are relatively ineffective. A survey of students showed that $26.2 \%$ of women and $43.3 \%$ of men receive information on nutrition from their trainer and teacher. They do not receive enough information on nutrition from media, radio and television. However, $26.2 \%$ of women and $18.5 \%$ of men receive such information via the Internet. When regulating body weight, women are mainly guided by their opinions, while men prefer coach recommendations.
\end{abstract}

Key words: athletes, nutrition, knowledge, information methods

\section{Introduction}

Knowledge and competences are important for every person, especially they are important for physically active people (Heaney, O'Connor, Michael, Giifford, \& Naughton, 2011; Carbone \& Zoellner 2012). Although the knowledge and competence of athletes about nutrition is investigated, this subject is still a relatively new area in the science of nutrition. The questionnaires on determining nutritional knowledge are designed (Trakman, Forsyth, Hoye, \& Belski, 2018), however, the criteria for assessing knowledge and competences of nutrition are still not sufficiently defined. Today there is no doubt that nutrition determines human health. Studies show that a healthy and balanced diet depends on knowledge about nutrition. Therefore, evaluating knowledge and nutritional competence, it should be noted that there is no single tool that would allow to reliably evaluate all of this (Silk et al., 2008). Knowledge and competence about nutrition is characterized as the ability of an individual to obtain, process and understand basic information on nutrition (Zoellner, Connell, Bouds, Crook, \& Yadrick, 2009).

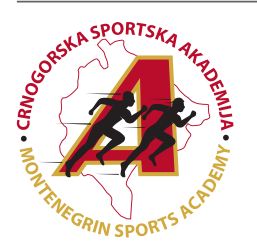

Correspondence:

Y. Yerzhanova

Al-Farabi Kazakh National University, Faculty Medicine and Health, Almaty, Kazakhstan

E-mail: eldana_777@mail.ru 
The following works were found on this subject Kolodinsky, Harvey-Berino, Berlin, Johnson, and Reynolds (2007), Kresic et al. (2009), Vitzthum et al. (2013), which presents data on the level of knowledge about nutrition of students in Croatia, Germany, Poland and the USA; Kelly, Mazzeo, and Bean (2012), Bojanic, Vasiljevic, Petkovic, and Muratovic (2015), exploring the knowledge of athletes about nutrition, believe that they can allow you to better plan the training process, reduce fatigue and allow the athlete to recover faster after exercise. According to the results of his research, Bojanic et al. (2015), the authors conclude that the knowledge of professional athletes of the Balkan countries in the field of sports nutrition is at a satisfactory level. Of the 787 athletes surveyed, only $65.5 \%$ noted a positive level of their knowledge about sports nutrition. The authors Janse van Rensburg, Sparks, Fletcher, \& Jansen van Rensburg (2018) who surveyed 2,550 amateur cyclists participating in long runs, concluded that athletes did not have enough knowledge about food additives consumed, carbohydrate consumption, as well as hydration strategies before and after prolonged physical exertion. Australian scientists Spronk, Heaney, Susan, Prvan, and O'Connor (2015), studied by survey the relationship between the general knowledge in the field of nutrition and nutrition quality of 101 athletes of high sportsmanship from four public sports institutions in $\mathrm{Au}-$ stralia, among which were 37 men and 64 women, mostly the team sports representatives. The results of their research showed that women's knowledge about sports nutrition was rated higher than men. There was no significant influence of the age of the investigated, level of education and sportsmanship. However, athletes who participated in previous dietary consultations had higher knowledge about nutrition (61.6\% versus $56.6 \%$; $\mathrm{p}=0.034)$. The authors concluded that counting the importance of nutrition for health and optimal athletic performance, intervention is recommended to improve knowledge about nutrition, especially for young male athletes. Results of American scientists Holden, Forester, Smith, Keshock, and Williford (2018), just as clearly indicate that athletes - students need additional support, training and education related to the knowledge of sports nutrition, had made an attempt to compare knowledge about nutrition of athletes of various sports. The result of this study indicates that athletes with increased stamina have a higher level of knowledge about nutrition in comparison with the representatives of other sports (Blennerhassett, Mc Naughton, Cronin, \& Sparks 2019).

Andrews, Wojcik, Boyd, and Bowers (2016), set the task to study the knowledge of sports nutrition of 123 athlete students, among whom were 47 women and 76 men, representatives of team sports, athletics, depending on gender, sports skills. The initial level of their knowledge about sports nutrition was $56.9 \%$, which was deemed not to be a sufficient level. There were no differences in sex, skill. After some consultations with a nutritionist, their level of knowledge in the field of sports nutrition increased to $75 \%$. Torres-McGehee et al. (2012), who studied the knowledge about nutrition of athletes, developing speed-strength qualities, found that the main source of knowledge about nutrition is trainers and information resources Ubeda et al. (2010), believes that the assessment of diet and eating habits, is of great importance for the maintenance of body weight of elite combat athletes. According to the authors, the consumption of some food groups by Spanish combat athletes does not always correspond to the recommendations, since their body weight is much higher than their competitive weight. Some authors (Lamarche et al., 2014), evaluating the knowledge about nutrition of trainers who train young athletes, found that the Internet was the most popular source of information on nutrition. Less than $30 \%$ of the interviewed trainers were able to correctly answer some general nutrition questions about carbohydrates and lipids. There is still relatively little research on knowledge and competence about nutrition of Kazakhstan athletes (Yerzhanova, Sabyrbek, Dilmakhanbetov, Madiyeva, \& Milaśius, 2018).

Knowledge and competence about nutrition of physically active individuals and athletes of Kazakhstan, their knowledge about nutrition is a relevant, not yet sufficiently studied problem. The purpose of the work is to determine the level of knowledge and the way of its acquisition by investigated sportsmen about habits and diet.

\section{Methods}

One hundred ninety-nine (199) students from Al-Farabi Kazakh National University and Abay Kazakh National Pedagogical University were enrolled in 1-4 courses in physical education and sports were engaged in the study of the level of knowledge, method of acquisition of information on nutrition. Among them were 42 women (W), whose average age was $19.1 \pm 1.3$ years, their average height was $166.1 \pm 7.5 \mathrm{~cm}$, body weight $57.5 \pm 8.8 \mathrm{~kg}$. Their body mass index (BMI) averaged $20.8 \pm 2.3$. Also, 157 men (M) participated in the questionnaire, whose average age was $20.2 \pm 2.3$ years, their average height was $177.3 \pm 8.6 \mathrm{~cm}$, and their body weight was $68.8 \pm 10.6 \mathrm{~kg}$. Their BMI averaged 21.8 \pm 2.4 .

The questionnaire prepared by Steptoe, Pollard, and Wardle (1995) was applied during the survey of students, directly interviewing each respondent. The questionnaire consisted of questions about socio-demographic data, (gender, age), physical development indicators (height, body weight, BMI), the level of physical activity studied during the week (the number of workouts and their duration), questions about the mode and eating habits, methods of obtaining knowledge about nutrition.

Sixty (60) athletes of high sportsmanship, among which were 15 volleyball players of Burevestnik teams, 15 judo wrestlers of the Kazakhstan national team, 15 wrestlers of the club team and 15 triathletes of the Kazakhstan national team were engaged in the study of the knowledge of information on nutrition in 2019. The age of volleyball players was 19-22 years old, their growth averaged $188.0 \pm 8.38 \mathrm{~cm}$, body weight - on average $78.11 \pm 7.68 \mathrm{~kg}$, BMI averaged 22.1. The age of Judaists was 20-28 years old, their average height was $174.3 \pm 8.3 \mathrm{~cm}$, body weight - on average $78.0 \pm 18.9 \mathrm{~kg}$, BMI averaged 25.74 . The age of the club team judo wrestlers was from 17 to 21 , their average height was $171.9 \pm 6.0 \mathrm{~cm}$, body weight $-71.0 \pm 16.1$ $\mathrm{kg}$, BMI - an average of 24.07. The triathlonists studied were 21-30 years old, their average height was $180.0 \pm 7.2 \mathrm{~cm}$, their body weight averaged $65.5 \pm 7.1 \mathrm{~kg}$, and the body mass index (BMI) averaged 20.2. The duration of filling up the questionnaire was not limited and averaged at about 30-45 minutes. The survey was carried out during the training camps at the venue.

Statistical analysis of the research data was carried out using the "Statistical Package for Social Sciences" program 
(SPSS, version 16). To analyze the results of the study, traditional methods of mathematical statistics were used - the arithmetic mean data (X) and their standard deviations (S) were calculated. To analyze the reliability of categorical data, the $\chi^{2}$ (chi-square) criterion was applied. The difference when $\mathrm{p}<0.05$ was considered reliable.

\section{Results}

The conducted questionnaire showed that, first of all, the information on nutrition the investigated students enrolled in the specialty of physical culture and sports receive from a coach, teacher. Thus, $26.2 \%$ of women $(\chi 2=21.000, \mathrm{df}=6$, $\mathrm{p}=0.002)$ and $43.3 \%$ of men $(\chi 2=193.930, \mathrm{df}=7, \mathrm{p}=0.000)$ indicated that knowledge about nutrition was obtained from their trainer. $23.8 \%$ of women and $24.8 \%$ of men receive such information from their parents. Relatively few investigated students used information from the media and friends about their nutrition (Table 1). The second most important source of information for women is the Internet that $26.2 \%$ of women use.

Table 1. Percentage distribution of respondents in response to the question "I get information on nutrition"

\begin{tabular}{|c|c|c|c|}
\hline № & Criteria & Women $(n=42)$ & Men $(n=157)$ \\
\hline 1 & Radio & $2.4 \%$ & $5.1 \%$ \\
\hline 2 & TV shows & $11.9 \%$ & $1.3 \%$ \\
\hline 3 & Parents & $23.8 \%$ & $24.8 \%$ \\
\hline 4 & Teacher, trainer & $x^{2}=21.000 ; d f=6 ; p=0.002$ & $x^{2}=193.930 ; d f=7 ; p=0.000$ \\
\hline 5 & Magazines, newspapers & $2.4 \%$ & $1.9 \%$ \\
\hline 6 & Friends & $7.1 \%$ & $5.1 \%$ \\
\hline 7 & Internet & $26.2 \%$ & $18.5 \%$ \\
\hline
\end{tabular}

For the students in the field of physical culture the main criteria for regulating body composition and food rationing is the help of the trainer in drawing up a nutrition program. This answer was chosen by $40.8 \%$ of the investigated men $(\chi 2=28.350 ; \mathrm{df}=3 ; \mathrm{p}=0.000)$, while $38.1 \%$ of women preferred self-training of the diet for weight control $(\chi 2=8.476 ; \mathrm{df}=3$; $\mathrm{p}=0.37)$. However, this sample was not statistically significant (Figure 1).

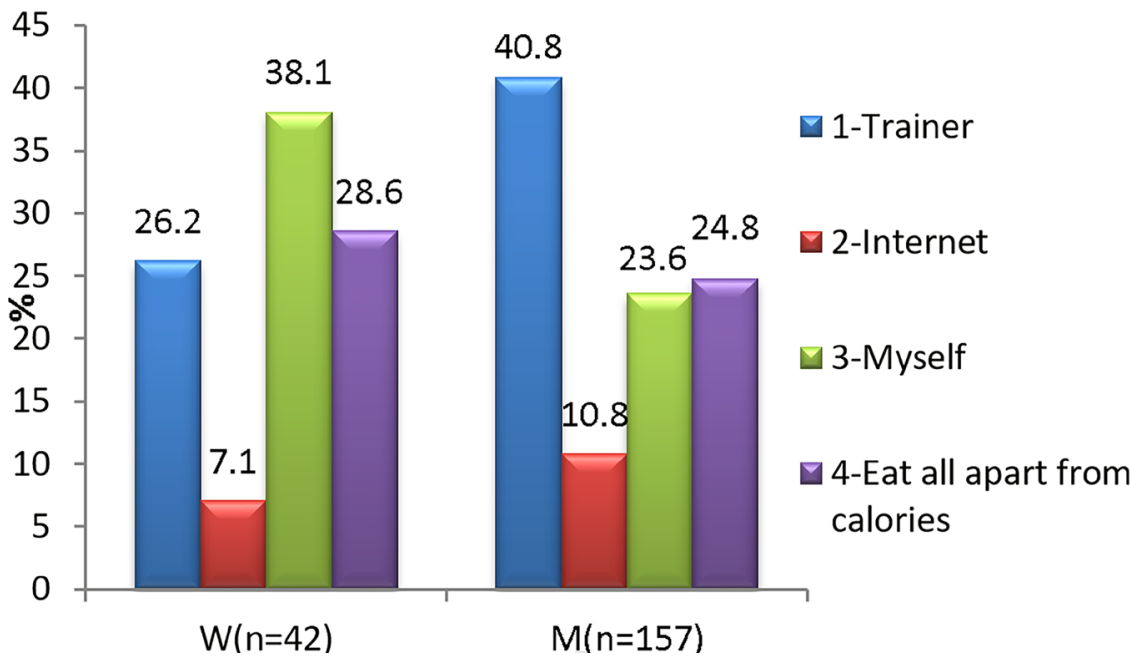

Figure 1. Percentage distribution of respondents in response to the question "I am guided in regulating body composition and compiling diet"

Upon assessing the answers of athletes of high sportsmanship to the question "Where do you get knowledge about nutrition?" the source of information on nutrition was determined. According to our survey, $36.6 \%$ of respo- ndents receive information on nutrition from their trainer, $20.0 \%$ from family members, $16.7 \%$ from other sources, less often from their nutritionist (10.0\%) and doctors $(8.3 \%)$ (Table 2).

Table 2. Percentage distribution of athletes by source of information on nutrition

\begin{tabular}{llccccc}
\hline No & Information sources & $\begin{array}{c}\text { Volleyball } \\
\text { players } \mathbf{n = 1 5}\end{array}$ & $\begin{array}{c}\text { Judokas of the } \\
\text { national team } \mathbf{n = 1 5}\end{array}$ & $\begin{array}{c}\text { Judokas of the } \\
\text { club team } \mathbf{n = 1 5}\end{array}$ & $\begin{array}{c}\text { Triathletes } \\
\mathbf{n = 1 5}\end{array}$ & $\overline{\mathbf{X}}$ \\
\hline 1 & Radio ant TV & 13.3 & 0 & 9 & 6.7 & 5.0 \\
2 & Doctors & 13.3 & 13.3 & 0 & 6.7 & 8.3 \\
3 & Reading popular literature & 6.7 & 20.0 & 0 & 13.3 & 1.7 \\
4 & Nutritionist & 6.7 & 20.0 & 0 & 13.3 & 10.0 \\
5 & Trainer & 40.0 & 20.0 & 53.4 & 33.3 & 36.6 \\
6 & Friends & 6.7 & 0 & 0 & 0 & 1.7 \\
7 & Family members & 13.3 & 26.7 & 33.3 & 6.7 & 20.0 \\
8 & Other sources & 0 & 20.0 & & & 33.3 \\
\hline
\end{tabular}


It should be noted that the level of knowledge essentially determines a healthier, appropriate nutrition.

\section{Discussion}

Knowledge about nutrition is an intermediary factor in choosing food that is able to enhance sportsmanship. Although athletes gain knowledge about nutrition from many information sources, however, according to many authors, the most important sources of knowledge about nutrition are trainers, relatives, friends, and radio and TV shows.

One of the factors that do not contribute to compliance with the rules of balanced nutrition of athletes is insufficient awareness of nutrition (M. Jessri, M. Jessri, RashidKhani, \& Zinn, 2010). Lack of awareness of nutrition may determine improper eating habits thereby retarding adaptation changes to physical exertion and hindering the achievement of high athletic performance. On the other hand, as some researchers note, the data presented does not always correspond to truth, which means that athletes do not always receive the correct information on nutrition (Mitchell, 2004; Gacek, 2007). Consequently, although the flow of scientific information on nutrition is quite large, athletes do not have enough information on it, they are not aware of the basic concepts of nutrition, so while training it is necessary to prepare and implement special educational programs containing basic knowledge about nutrition (Zawila, Steib, \& Hoogenboom, 2003; Froiland, Koszewski, Hingst, \& Kopecky, 2004; Nowacka, Leszczyńska, Kopeć, \& Hojka, 2016).

According to our research, the main source of information about nutrition is the trainer, from which the knowledge about nutrition is obtained by average $36.7 \%$ of the Kazakhstan athletes of high sportsmanship investigated by us. $26.2 \%$ of female students and $43.3 \%$ of male students enrolled in the program of physical culture and sports receive the most information from the trainer and teacher. On the other hand, knowledge about nutrition can determine sociodemographic factors: gender, age, specificity of the sport (Dunn, Turner, \& Denny, 2007; Rash, Malinauskas, Duffrin, Barber-Heidal, \& Overton, 2008, Nazni \& Vimala, 2010), who studied the level of knowledge, determined that it depends from the education of the athlete. However, there is evidence that many athletes are not enough aware of good nutrition and proper diet. Rosenbloom, Jonnalagadda, and Skinner (2002), Zawila et al. (2003), Dunn et al. (2007), Rash et al. (2008) note that the main problem facing the youth of colleges and universities in America today is the easy availability of fast food or easily cooked food. Current research shows that as athletes become more knowledgeable, the quality of food consumption improves (Kunkel, Bell, \& Luccia, 2001). The scientific literature notes that qualified knowledge about nutrition can improve nutritional status. Zawila et al. (2003) points out that athletes obtaine information on nutrition from public audiovisual media, the Internet, popular literature, friends, and family members. Birch and Fisher (1998) pays special attention to the role of parents in the nutrition of athletes, especially young ones, determining what, when and how much they should eat excluding their self-control. Our studies have shown that nutrition programs prepared by the trainer play the main role for men $(43.8 \%)$, while women (38.1\%) prefer to compile these programs by themselves. Juzwiak and Ancona-Lopez (2004) note that specific dietary tips on nutrition for Brazilian athletes were recommended by 93 and $46 \%$ of the investigated trainers before and after the competition respectively. In this regard, the trainer must have not only a training methodology, but also a sufficient amount of physiological knowledge. On the other hand, as the results of some researchers show, the level of knowledge of trainers about nutrition is not sufficient (Jazayeri \& Amani, 2004; Torres-Mc Gehee et al., 2012), and information sources (TV, radio programs, popular literature, friends, family members) do not always provide athletes with the qualified information on nutrition (Jessri et al., 2010; Nazni \& Vimala, 2010).

Kazakhstani athletes get basic information about nutrition from trainers and family members, and too few are accounted for by doctors and nutritionists. Public information systems are relatively ineffective. A survey of students showed that $26.2 \%$ of women and $43.3 \%$ of men receive information on nutrition from a trainer and teacher. As well as sportsmen of high sportsmanship, students indicate that they receive the most information from their trainer or teacher $-26.2 \%$ and $43.3 \%$ of respondents, respectively. They do not receive enough information about nutrition from media, radio and television. However, $26.2 \%$ of women and $18.5 \%$ of men receive such information via the Internet.

Data of our research allow to assume that Kazakhstani athletes lack motivation to comply with the requirements of good nutrition, therefore, regardless of the available knowledge about nutrition, their eating habits do not always meet the requirements of healthy nutrition.

Acknowledgements

There are no acknowledgements.

\section{Conflict of Interest}

The authors declare that there are no conflicts of interest.

Received: 03 April 2019 | Accepted: 11 May 2019 | Published: 01 June 2019

\section{References}

Andrews, A., Wojcik, J., Boyd, J., \& Bowers, C. (2016). Sports nutrition knowledge among mid-major division I university student-athletes. Journal of Nutrition and Metabolism. ID. 3172460. http://dx.doi. org/10.1155/2016/3172460

Birch, L., \& Fisher, J. (1998). Development of eating behaviors among children and adolescents. Pediatrics, 101(3 Pt 2), 539-549.

Blennerhassett, C., McNaughton, L., Cronin, L., \& Sparks, S. (2019). Andy development and implementation of a nutrition knowledge questionnaire for ultraendurance athletes. International Journal of Sport Nutrition \& Exercise Metabolism, 29(1), 39-45.

Bojanic, D., Vasiljevic, I., Petkovic, J., \& Muratovic, A. (2015). Athletes' knowledge of reduced sports nutrition. Sport Mont, XIII(43-45), 94-95.

Carbone E., \& Zoellner J. (2012). Nutrition and health literacy: a systematic review to inform nutrition research and practice. Journal of the Academy of Nutrition and Dietetics, 112(2), 254-265.

Dunn, D., Turner, L.W., \& Denny, G. (2007). Nutrition knowledge and attitudes of college athletes. The Sport Journal, 10(4), 45-53.

Froiland, K, Koszewski, W, Hingst, J, \& Kopecky, L. (2004). Nutritional supplement use among college athletes and their sources of information. International Journal of Sport Nutrition and Exercise Metabolism, 14,104120.

Gacek, M. (2007). Knowledge and nutritional behaviours among youth practising sports at school of sports championship in Cracov. Rocznik Panstwowego Zakladu Higieny, 58(4), 641-649.

Heaney, S., O'Connor, H., Michael, S., Giifford, J., \& Naughton, G. (2011). Nutrition knowledge in athletes: a systematic review. International Journal of Sport Nutrition and Exercise Metabolism, 21, 248-261.

Holden, S., Forester, B., Smith, A., Keshock, Ch., \& Williford, H. (2018). Nutritional knowledge of collegiate athletes. Applied Research in Coaching and Athletics Annual, 33, 65-77.

Jazayeri, M., \& Amani, R (2004). Nutritional knowledge and practices of bodybuilding trainers in Ahwaz, Iran. Pakistan. Journal of Nutrition, 3(4), 228-231. https://doi.org/10.3923/pjn.2004.228.231 
Jessri, M., Jessri, M., RashidKhani, B., \& Zinn, C (2010). Evaluation of Iranian college athletes sport nutrition knowledge. International Journal of Sport Nutrition and Exercise Metabolism, 20, 257-263. https://doi. org/10.1123/ijsnem.20.3.257.

Juzwiak, C., \& Ancona-Lopez, F (2004). Evaluation of nutrition knowledge and dietary recommendations by coaches of adolescent Brazilian athletes. International. Journal of Sport Nutrition and Exercise Metabolism, 14(2), 222 235. https://doi.org/10.1123/ijsnem.14.2.222

Kelly, N., Mazzeo, S., \& Bean, M (2012). Systematic review of dietary interventions with college students: Directions for future research and practice. Journal of Nutrition Education and Behavior, 45, 304-313.

Kolodinsky, J., Harvey-Berino, J., Berlin, L., Johnson, R., \& Reynolds T (2007). Knowledge of current dietary guidelines and food choice by college students: better eaters have higher knowledge of dietary guidance. Journal of the American Dietetic Association, 107(8), 1409-1413.

Kresic, G., Jovanovic, G., Pavicic Žeželj, S., Cvijanovic, O., \& Ivezic, G (2009). The effect of nutrition knowledge on dietary intake among Croatian university students. Collegium Anthropological, 33(4), 1047-1056.

Kunkel, M., Bell, L., \& Luccia, B. (2001). Peer nutrition education program to improve nutrition knowledge of female collegiate athletes. Journa of Nutrition Education, 33(2), 114-115. https://doi.org/10.1016/S14994046(06)60175-9.

Lamarche, B., Morissette, E., Provencher, V., Valois, P.,Goulet, C., \& Drapeau, V. (2015). Institute of Nutraceuticals and Functional Foods, Laval University, Québec, QC, Canada. International Journal of Sport Nutrition and Exercise Metabolism, 25(4), 326-34.

Mitchell, C. (2004). Nutritional knowledge of high school athletes. West Virginia University School of Physical Education Thesis.

Nazni, P., \& Vimala, S. (2010). Nutrition knowledge, attitude and practice of college sportsmen. Asian Journal of Sports Medicine, 1(2), 93-100.

Nowacka, E, Leszczyńska, T, Kopeć, A, \& Hojka, D. (2016). Nutritional behavior of Polish canoeist's athletes: The interest of nutritional education. Science and Sports, 31(4), 79. https://doi.org/10.1016/j.scispo.2016.04.002.

Rash, C, Malinauskas, B, Duffrin, M, Barber-Heidal, K, \& Overton, R. (2008). Nutrition-related knowledge, attitude, and dietary intake of college track athletes. The Sport Journal, 11(4), 48-56.

Rosenbloom, C., Jonnalagadda, S., \& Skinner, R. (2002). Nutrition knowledge of collegiate athletes in a Division I National Collegiate Athletic Association institution. Journal of the American Dietetic Association, 103, 418-421. https://doi.org/10.1016/S0002-8223(02)90098-2.
Silk, K., Sherry, J., Winn, B., Keesecker, N., \& Horodynski, M., et al. (2008) Increasing nutrition literacy: testing the effectiveness of print, web site, and game modalities. Journal Nutrition Education Behavior, 40, 3-10.

Janse van Rensburg, D., Sparks, I., Fletcher, L., \& Jansen van Rensburg, A. (2018). A cross-sectional study of 2550 amateur cyclists shows lack of knowledge regarding relevant sports nutrition guidelines. South African Journal of Sports Medicine, 30(1), 1-6.

Spronk, I., Heaney, Susan, E., Prvan, T., \& O'Conno, H. (2015). Relationship between general nutrition knowledge and dietary quality in elite athletes. International Journal of Sport Nutrition and Exercise Metabolism, 25(3), 243251

Steptoe, A., Pollard, T.M., \& Wardle, J. (1995). Development of a measure of the motives underlying the selection of food: the food choice questionnaire. Appetite, 25, 267-284

Torres-Mc Gehee, T.M., Pritchett, K.L., Zippel, D., Minton, D.M., Cellamare. A., \& Sibilia, M. (2012). Sports nutrition knowledge among collegiate athletes, coaches, athletic trainers, and strength and conditioning specialists. Journal of Athletic Training, 47(2), 205-207.

Trakman, G., Forsyth, A., Hoye, R., \& Belski, R. (2018). Development and validation of a brief general and sports nutrition knowledge questionnaire and assessment of athletes' nutrition knowledge. Journal of the International Society of Sports Nutrition, 15(17), 1-8.

Ubeda, N., Palacios Gil-Antunano, N., Montalvo Zenarruzabeitia, Z., Garcia, J.B. Garcia, A., \& Iglesias-Gutiérrez, E. (2010). Food habits and body composition of Spanish elite athletes in combat sports. Nutricion Hospitalaria, 25(3), 414-421.

Vitzthum, K., Endres, E., Koch, F., Groneberg, D., Quarcoo, D., \& Mache, S. et al., (2013). Eating behavior and nutrition knowledge among musical theatre students. Medical Problems of Performing Artists, 28(1), 19-23.

Yerzhanova, Y., Sabyrbek, Zh., Dilmakhanbetov, E., Madiyeva, G., \& Milaśius, K. (2018). Mode and food habits of athletes of Kazakhstan. Pedagogics, Psychology, Medical-Biological Problems of Physical Training and Sport, 22(6), 328-334. https:// doi.org/10.15561/18189172.2018.0608

Zawila, L., Steib, C., \& Hoogenboom, B. (2003). The female collegiate cross-country runner: Nutritional knowledge and attitudes. Journal of Athletic Training, 38(1), 67-74.

Zoellner, J., Connell, C, Bouds, W. Crook, L, \& Yadrick, K, (2009). Nutrition literacy status and preferred nutrition communication channels among adults in the Lower Mississippi Delta. Preventing Chronic Disease, 6(4), A 128. 